\title{
THE MAINTENANCE OF A SUSTAINED THROMBOLYTIC STATE IN MAN. I. INDUCTION AND EFFECTS *
}

\author{
BY ANTHONY P. FLETCHER, NORMA ALKJAERSIG AND SOL SHERRY
}

(From the Department of Medicine, Washington University School of Medicine, St. Louis, Mo.)

(Submitted for publication October 24, 1958; accepted February 6, 1959)

Streptokinase, a product of hemolytic streptococcal metabolism, is a highly effective activator of human plasminogen. Plasmin, the enzyme formed following plasminogen activation, exerts powerful proteolytic and fibrinolytic effects at neutral hydrogen ion concentrations, which in vivo mediate the mechanisms of physiological fibrinolysis. Consequently, hopes have been entertained that the intravenous injection of streptokinase, or of streptokinase-activated plasmin, might prove to be of benefit in the therapy of human thromboembolic disease.

Animal experiment, despite the lessened effectiveness of streptokinase as an activator of animal plasminogen and the difficulties of species variability, has yielded striking findings. The intravenous injection of very large doses of streptokinase has been shown to produce lysis of artificially produced thrombi in the arteries of dogs (1) and in the veins of rabbits (2), to cause the clearance of peritoneal exudate evoked by trauma (3) and more recently to prevent or remove fibrinoid lesions secondary to the generalized Shwartzman response (4). These findings appear to be of unequivocal significance but the precise mechanism of their production has been uncertain.

Human experiment has so far been of limited scope. Tillett, Johnson and McCarty (5) were the first to demonstrate that the intravenous injection of relatively small doses of streptokinase would induce a short-lived fibrinolytic state in man. Their findings were, of necessity, exploratory as the streptokinase preparations available to them were impure and caused pyrogenic and hypotensive effects. Similarly investigations made using streptokinase-activated plasminogen have

* This work was supported by grants from the National Heart Institute (H3745), United States Public Health Service, Bethesda, Md., and Lederle Laboratories Division, American Cyanamid Co., Pearl River, N. Y. been limited by the clinical toxicity $(6,7)$ and the low potency and instability of the available preparations.

However, earlier experimental limitations have now largely disappeared as the development of streptokinase purification methods (8) has resulted in the availability of highly purified streptokinase, which is virtually devoid of toxicity to man (9). Furthermore, better understanding of the role of streptokinase antibody in the inhibition of the fibrinolytic response to streptokinase infusion and a knowledge of plasma streptokinase clearance rates under a variety of immunological circumstances (10) now allows of considerable variation in and control of experimental conditions.

The preceding paper (11) cites evidence to show that the chief and primary mechanism of thrombolysis involves the diffusion or adsorption of plasminogen activator to the thrombus, activation of intrinsic thrombus plasminogen and thrombolysis. The secondary mechanism of direct thrombus digestion by extrinsic plasmin is of little quantitative importance. These findings on mechanisms causing thrombus dissolution have important therapeutic as well as physiologic implications. The use of streptokinase as a plasminogen activator requires either that dosage be regulated to maintain maximum plasmin concentrations or that dosage be regulated to obtain high levels of activator concentration. The rapid fall of plasma plasminogen concentration occurring in the presence of high levels of circulating activator renders the two states mutually exclusive. For the reason cited above we have regulated streptokinase dosage to obtain high levels of activator concentration.

Hitherto no distinction has been made between the two mechanisms of clot lysis described above. We have proposed (11) and have used, in this communication, the term thrombolytic to designate the process of thrombolysis, i.e., the lysis 
of a preformed clot, ${ }^{1}$ a phenomenon mainly dependent on the concentration of surrounding plasminogen activator. We have restricted the use of the term fibrinolytic to its original meaning to indicate the action of a proteolytic enzyme acting primarily upon a fibrin substrate but also acting upon such other substrates as are susceptible to its action.

It is the purpose of the present communication to describe the physiological and biochemical changes resulting from the intravenous infusion at high dosage of streptokinase in man. Since the direct toxic effects of streptokinase were minimal, the study constitutes an investigation of the biological effects of an intense and prolonged thrombolytic state in the human. The results indicate that, at least under restricted circumstances, this state is tolerated without deleterious consequences and may be applied to the treatment of thromboembolic disease in man. The clinical effects of such a sustained thrombolytic state are described in an accompanying article (12).

\section{MATERIALS AND METHODS}

The observations reported in this communication were made on 50 hospitalized patients suffering from thromboembolic disease, who received streptokinase therapy ${ }^{2}$ (12). Blood specimens were collected into oxalate tubes, $0.8 \mathrm{ml}$. of 5 per cent potassium oxalate being used for $10 \mathrm{ml}$. of blood. One $\mathrm{ml}$. of blood was collected into a plain $75 \times 6 \mathrm{~mm}$. tube and incubated at $37^{\circ} \mathrm{C}$. for observation of the whole blood fibrinolysis rate. Specimens for platelet counts were collected in ethylenediaminetetraacetic acid (EDTA) tubes. Sedimentation rates and hematocrit determinations were performed in standard Wintrobe tubes. Assay methods for all components of the plasminogen plasmin system and for fibrinogen ${ }^{8}$ were as previously described (11).

1 This usage corresponds to the literal meaning and original derivation of the word (Oxford English Dictionary) and its use does not imply specific reference to pathological states where intravascular thrombi may vary in composition.

2 Observations on a preliminary series of 36 patients (15) although used to develop the present methods are excluded from this report.

${ }^{3}$ Since this method depends on complete conversion of fibrinogen to fibrin, some values quoted later may be in error, because until the presence of antithrombin activity was detected in certain of our plasma samples, only a one hour precipitation time was used. Later highly reproducible duplicate assays were obtained by using a 10 hour precipitation period.
Streptokinase was isotopically labeled and its plasma concentration determined in patients by previously described methods (10). Quantitative paper electrophoretic determinations were made with a Spinco $4 R$ apparatus using standard staining and elution methods (13).

Antiplasmin assay. The antiplasmin activity of plasma was assayed by incubating the plasma with spontaneously activated human plasmin containing 3.5 casein units per $\mathrm{ml}$. (14) and determining the degree of inhibition produced. Plasmin aliquots $(0.5 \mathrm{ml}$. containing 1.75 casein units) were incubated with $0.2 \mathrm{ml} ., 0.1 \mathrm{ml}$. and $0.05 \mathrm{ml}$. of the test plasma for 15 minutes at $37^{\circ} \mathrm{C}$. Each sample was then assayed for residual plasmin by the casein method and the result expressed as percentage inhibition of the original plasmin solution. Though the inhibition of plasmin by plasma is approximately related to the log plasma concentration, we have not calculated absolute antiplasmin values since these values depend, to a degree, upon the conditions of measurement.

Urokinase lysis time. This test facilitates differentiation between the presence of streptokinase antibody and plasmin inhibitors in plasma. Two-tenths $\mathrm{ml}$. of plasma plus $0.1 \mathrm{ml}$. urokinase $(0.5 \mathrm{mg} \text {. per } \mathrm{ml} .)^{5}$ were clotted with $0.1 \mathrm{ml}$. thrombin (20 units per $\mathrm{ml}$.) and observed for plasma fibrinolysis at $37^{\circ} \mathrm{C}$.

One stage prothrombin times were determined by the method of Quick (16) using rabbit brain thromboplastin. ${ }^{6}$ The same batch of thromboplastin was used throughout and normal one stage times were $15.2 \pm 1.1$ seconds.

Two stage prothrombin assays were determined by the method of Ware and Seegers (17) modified by the use of dextran (final concentration 0.6 per cent) rather than acacia in the incubation mixture. Standard plasma? was used as a control and gave an assay reading of 275 prothrombin units per $\mathrm{ml}$.

Accelerator globulin ( $A c G$ ) concentrations were routinely determined by the method of Deutsch and Schaden (18) and in some patients the method of Ware and Seegers (19) was also employed to check the findings. Cognizance was taken of the increased antithrombin values shown in some plasmas and its effect upon the AcG values was eliminated by appropriate specimen dilution.

Antithrombin assay. The clotting time of a patient's plasma by the addition of a standard thrombin solution was used as a measure of antithrombin activity. Parke, Davis thrombin was dissolved in a mixture of equal parts of glycerol and saline to a concentration of $100 \mathrm{U}$ per $\mathrm{ml}$. and stored at $-20^{\circ} \mathrm{C}$. Immediately before use this thrombin was diluted with saline $1: 10$. To $0.1 \mathrm{ml}$. of the patient's plasma was added $0.3 \mathrm{ml}$. thrombin titration mixture (20). One-tenth $\mathrm{ml}$. thrombin, $10 \mathrm{U}$ per $\mathrm{ml}$., was blown into the mixture and the clotting time

4 Spinco/Beckman Instruments, Berkeley, Cal.

${ }^{5}$ Kindly supplied by Dr. J. Ploug, Leo Pharmaceuticals, Copenhagen.

- Permaplastin, C. W. Alban Co., St. Louis, Mo.

${ }^{7}$ Diagnostic plasma, Warner-Chilcott, Morris Plains, 


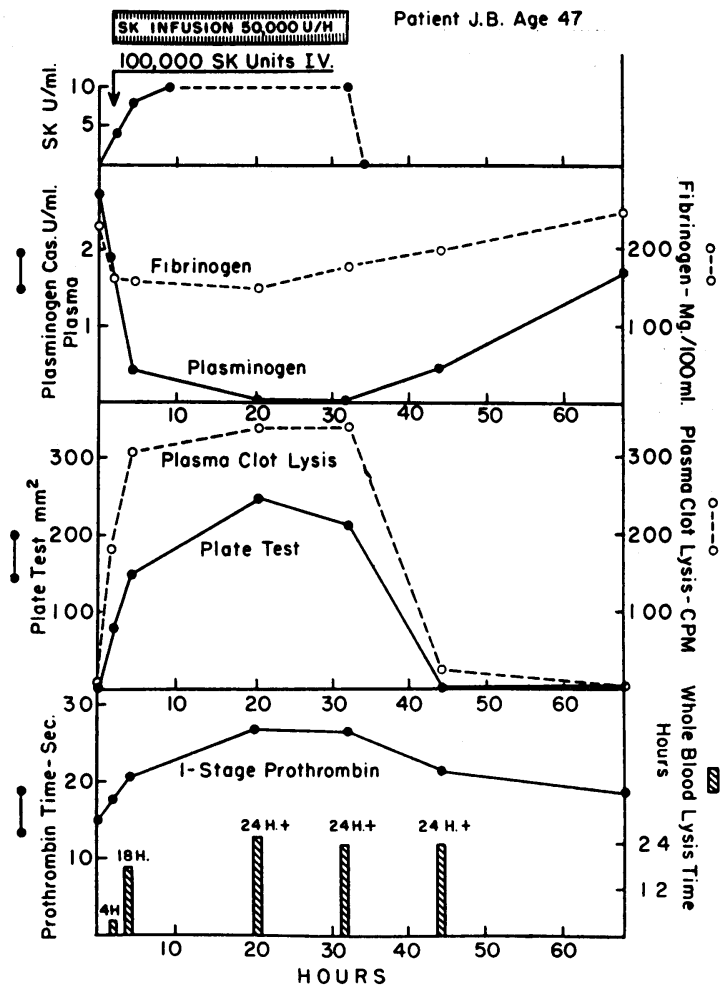

Fig. 1. Serial Biochemical Determinations in a Patient Receiving Streptokinase Therapy

The infusion and the thrombolytic state were of 30 hours' duration.

noted. The thrombin titration mixture was added to give a sharper end point and shorter clotting times; furthermore our results were far more reproducible by this method than without the thrombin titration mixture. Clotting times of normal plasmas performed in this manner were $9.9 \pm 1.1$ seconds.

Transaminase $(S-G O T)$ was determined by the method of Karmen, Wróblewski and LaDue (21).

Method of streptokinase administration. The streptokinase preparations ${ }^{8}$ used, assayed at 600 to 700 streptokinase units per $\mu \mathrm{g}$. nitrogen, were biophysically homogenous and though showing evidence of nonhomogeniety on immunochemical analysis were devoid of other than streptokinase activity.

The plasmas of patients were assayed for their total content of streptokinase inhibitory constituents (antibody and antiplasmin) by means of the predicted dose test (22). Since the purpose of the initial priming dose of streptokinase was to induce a rapid fall of plasma plasminogen, this dose was calculated using a 20 minute test end point rather than the 120 minute end point previously described (22); the effect of this change was to approximately double the streptokinase concentration

8 Kindly supplied by Dr. J. Ruegsegger, Lederle Laboratories Division of American Cyanamid, Pearl River, N. Y. reading per $\mathrm{ml}$. plasma. Thus the initial streptokinase dose required for each patient was calculated by multiplying the number of streptokinase units required to produce plasma fibrinolysis in $1 \mathrm{ml}$. plasma in 20 minutes by the patient's calculated plasma volume. This initial dose varied between 35,000 and 1,500,000 units for individual patients and was dependent chiefly upon the patient's plasma antibody level; it was injected intravenously over a 10 to 40 minute period. Samples withdrawn following this procedure invariably showed brisk whole blood fibrinolysis. Expressed as a frequency distribution, the initial dose of streptokinase employed was less than 50,000 units in 35 patients, 50,000 to 100,000 units in 19 patients, 100,000 units to $1,000,000$ units in 19 patients and over 1,000,000 units in three patients. Analysis of this frequency distribution against a similar one (22) showed that our patients needed substantially less streptokinase as an initial dose than had been previously calculated ( $\chi^{2}$ equals 17.6 for five degrees of freedom and $0.01>\mathrm{p}>0.001)$.

Infusions were usually given into a foot vein and the requisite constant delivery rate maintained by the use of a mechanical syringe driver. ${ }^{9}$ Streptokinase dissolved at appropriate concentrations in normal saline was administered at the rate of $7 \mathrm{ml}$. per hour; these solutions maintained at $25^{\circ} \mathrm{C}$. were stable for more than 24 hours. The infusion schedules were based on a study of plasma streptokinase clearance rates made with isotopically labeled streptokinase (10) and checked by determination of actual plasma streptokinase concentrations, using similar methods. In practice, it was found that patients receiving an initial priming dose of streptokinase of 50,000 units or less required a sustaining infusion at the rate of 35,000 streptokinase units per hour. Those receiving an initial dose of 50,000 to 100,000 units required a sustaining infusion at the rate of 50,000 units per hour, and those receiving an initial dose of over 100,000 units required 100,000 to 150,000 units per hour. The mean plasma streptokinase concentration obtained by sampling during the infusion periods was 8.5 streptokinase units per ml. plasma with a range of three to 19 streptokinase units per ml. plasma (21 observations made with isotopically labeled streptokinase in five patients). These figures and the consistent biochemical data, quoted later, indicate that the infusion schedules provided effective concentrations of streptokinase and plasma activator throughout the infusion period. The duration of the infusions varied from six to 48 hours.

\section{RESULTS}

\section{Changes in fibrinolytic moieties during strepto- kinase therapy}

Figure 1 illustrates biochemical changes following the injection of 100,000 units of streptokinase given as a priming dose and 50,000 streptokinase

${ }^{9}$ Bird Kymograph Driver, Phipps and Bird, Inc., Richmond, Va. 
units per hour for 30 hours as a sustaining infusion; these changes were typical of those found in this series. The patient, a 47 year old male, suffering from pulmonary embolism, also received tracer doses of isotopically labeled streptokinase in both the priming injection and in the sustaining infusion for the purpose of measuring plasma streptokinase concentrations. So as to limit the quantity of administered radioactivity to $30 \mu \mathrm{c}$., the isotopically labeled streptokinase infusion was given only over the first eight hour period and plasma streptokinase concentrations beyond this period have been calculated (interrupted line in Figure 1).

The priming dose of streptokinase, though largely cleared from the plasma in combination with antibody, sets in train a number of biochemical changes, which rapidly become complete and stabilize under the action of the sustaining infusion. As plasma streptokinase concentration increased, plasminogen was rapidly and completely activated to plasmin and the plasma plasminogen concentration fell to zero or trace levels. The relatively high and constant plasma streptokinase concentration, maintained throughout the infusion period, caused immediate activation of plasminogen entering the circulation and as a consequence plasma plasminogen concentration remained at near zero or trace levels. Despite the complete activation of available plasminogen to plasmin, assay for this enzyme in the plasma of patients who received streptokinase has revealed that plasma inhibitory mechanisms were so effective and rapid in action that only minimal proteolytic activity could be detected, i.e., usually less than 5 per cent of the potential activity (11). Such residual proteolytic activity, highest at the start and during the first few hours after the start of the infusion, caused among other changes (vide infra) an initial drop of plasma fibrinogen concentration (approximately 30 per cent). However, following the initial drop, the level stabilized and indeed, in some patients, actually slowly increased as the infusion was continued.

Concomitantly with the initial rise of plasma streptokinase concentration, intense plasma thrombolytic activity developed. Thrombolytic activity, as measured by both the rate of digestion of isotopically labeled clots and by the fibrin plate technique, remained greatly elevated throughout the duration of the infusion and declined abruptly upon its cessation. That this effect is due to the presence of plasminogen activator rather than to the presence of the enzyme plasmin in the patient's plasma has been demonstrated by activating or removing plasminogen from the assay systems. Either heating the fibrin plate to denature plasminogen or washing the isotopically labeled clots to elute plasminogen results in test systems insusceptible to the action of patient's plasma but susceptible to the action of plasmin (11).

Whole blood fibrinolysis times reflect the composite biochemical changes shown in Figure 1 and though enhanced by the presence of plasmin, depend primarily upon the rate at which plasminogen is being activated within the formed clot (23), a phenomenon dependent on the plasminogen and activator concentrations of the plasma from which the clot was formed. The specimen drawn 30 minutes after the start of the infusion contained 60 per cent of its original plasminogen concentration and the resulting clot, though somewhat deficient in plasminogen, lysed in four hours under the influence of plasminogen activator present at this time. At three hours, though the plasminogen activator concentration was approximately double that in the previous specimen, clot lysis did not occur for 18 hours as the clot was formed from plasma containing only 10 per cent of its normal plasminogen content. At 20 and 30 hours, though plasminogen activator was still present in high concentration, neither clot lysed during the period of observation as they were formed from plasminogen-free plasma. The failure of clot lysis at 45 hours (15 hours after the cessation of the infusion) was due to lack of plasminogen activator, since this material disappears from the plasma two to four hours after the termination of the infusion. Stress is laid upon the phenomenon of whole blood fibrinolysis as it has implications important to the clinical safety of the induced thrombolytic state.

Figure 1 shows that the patient developed a coagulation anomaly evinced by a rise in the one stage prothrombin time from a normal of $15 \mathrm{sec}-$ onds to a high of 26 seconds at which level the prothrombin time stabilized until it returned to normal after termination of the infusion. All patients receiving streptokinase have developed a similar anomaly, though to varying degree, and its 
TABLE I

Changes in fibrinolytic moieties during streptokinase therapy *

\begin{tabular}{|c|c|c|c|c|c|c|c|c|}
\hline $\begin{array}{l}\text { Time of sample... } \\
\text { Sample no........ }\end{array}$ & $\begin{array}{l}0 \\
0\end{array}$ & $\begin{array}{c}30 \text { mins. } \\
\text { I }\end{array}$ & $\begin{array}{c}2-3 \mathrm{hrs} . \\
\text { II }\end{array}$ & $\begin{array}{c}\text { 6-8 hrs. } \\
\text { III }\end{array}$ & $\begin{array}{c}14-20 \mathrm{hrs} . \\
\text { IV }\end{array}$ & $\begin{array}{c}22-27 \text { hrs. } \\
\text { V }\end{array}$ & $\begin{array}{c}28-32 \text { hrs. } \\
\text { VI }\end{array}$ & $\begin{array}{l}8-12 \mathrm{hrs} . \\
\text { after } \\
\text { infusion }\end{array}$ \\
\hline Plate test, $m m .^{2}$ & 0 & $\begin{array}{c}142 \pm 108 \\
(393-0)\end{array}$ & $\begin{array}{c}241 \pm 95 \\
(440-133)\end{array}$ & $\begin{array}{c}230 \pm 84 \\
(425-144)\end{array}$ & $\begin{array}{l}220 \pm 95 \\
(420-85)\end{array}$ & $\begin{array}{c}194 \pm 81 \\
(377-101)\end{array}$ & $\begin{array}{l}156 \pm 56 \\
(246-75)\end{array}$ & 0 \\
\hline $\begin{array}{l}\text { Fibrinogen, } \\
m g . / 100 \mathrm{ml} .\end{array}$ & $\begin{array}{c}334 \pm 86 \\
(475-153)\end{array}$ & $\begin{array}{c}278 \pm 71 \\
(403-144)\end{array}$ & $\begin{array}{c}221 \pm 93 \\
(412-103)\end{array}$ & $\begin{array}{l}211 \pm 83 \\
(371-84)\end{array}$ & $\begin{array}{l}183 \pm 76 \\
(334-67)\end{array}$ & $\begin{array}{l}204 \pm 89 \\
(350-67)\end{array}$ & $\begin{array}{c}205 \pm 70 \\
(344-104)\end{array}$ & $\begin{array}{c}240 \pm 51 \\
(334-146)\end{array}$ \\
\hline $\begin{array}{l}\text { Plasminogen, } \\
\text { cas. } U / m l .\end{array}$ & $\begin{array}{l}2.46 \pm 0.92 \\
(4.00-1.08)\end{array}$ & $\begin{array}{l}1.26 \pm 0.73 \\
(2.87-0.17)\end{array}$ & $\begin{array}{l}0.35 \pm 0.43 \\
(1.52-0)\end{array}$ & $\begin{array}{l}0.13 \pm 0.14 \\
(0.48-0)\end{array}$ & $\begin{array}{l}0.22 \pm 0.27 \\
\quad(1.0-0)\end{array}$ & $\begin{array}{c}0.11 \pm 0.16 \\
(0.54-0)\end{array}$ & $\begin{array}{l}0.10 \pm 0.08 \\
(0.29-0)\end{array}$ & $\begin{array}{r}1.08 \pm 0.53 \\
(2.16-0.20)\end{array}$ \\
\hline $\begin{array}{l}\text { Clot lysis, } \\
\text { cpm in supnt. }\end{array}$ & 0 & $\begin{array}{c}190 \pm 118 \\
(398-5)\end{array}$ & $\begin{array}{c}381 \pm 310 \\
(1,000-80)\end{array}$ & $\begin{array}{l}354 \pm 155 \\
(570-99)\end{array}$ & $\begin{array}{l}451 \pm 247 \\
(805-100)\end{array}$ & $\begin{array}{c}288 \pm 171 \\
(583-75)\end{array}$ & $\begin{array}{l}277 \pm 104 \\
(410-100)\end{array}$ & 0 \\
\hline $\begin{array}{l}\text { Whole blood } \\
\text { fibrinolysis, } \\
\text { hours }\end{array}$ & $24+$ & $\stackrel{3}{(0.5-24+)}$ & $\begin{array}{c}3 \\
(0.5-24+)\end{array}$ & $\begin{array}{c}5 \\
(3-24+)\end{array}$ & $\stackrel{14}{(6-24+)}$ & $\begin{array}{c}21 \\
(18-24+)\end{array}$ & $\stackrel{23}{(18-24+)}$ & $24+$ \\
\hline
\end{tabular}

* Biochemical changes observed in 21 patients. (Mean and standard deviations are given with range of observations in parentheses.) Ten patients in this group received supplemental hydrocortisone and the data given for plate test, fibrinogen, plasminogen and radioactive clot lysis includes these patients. However the data given for whole blood fibrinolysis was that obtained in the nonsteroid treated group.

pathogenesis with the means for its control are discussed in a later section.

Table I embodies data obtained from analyses made on 128 blood samples drawn from 21 patients who received continuous streptokinase treatment for 30 hours. Biochemical data obtained from 29 other patients differed in no respect from that recorded in Table I, but since some of the findings referred to infusions of differing duration and in others serial sampling was more widely spaced, the data have not been incorporated. Intravenous hydrocortisone was administered before and during the treatment to 10 of the 21 patients, but since analysis showed no significant differences $(p>0.1$ in all instances) between the steroid and the nonsteroid treated groups, the data for plasminogen, fibrinogen, fibrin plate test and isotopic clot assay given in Table I represent the combined values from both groups. However hydrocortisone administration did affect other phases of the thrombolytic state and the times for whole blood fibrinolysis given in Table I refer only to patients not given steroids.

It is apparent from the mean values for the biochemical determinations and their comparatively narrow standard deviations (Table I) that the injection of an appropriate priming dose and a sufficient sustaining infusion of streptokinase will cause predictable and highly reproducible biochemical changes in patients. Though the dosage schedule described earlier was initially used in all patients, in some 10 per cent of them the infusion rate was increased if analysis of samples drawn within the first six hours showed an insufficiently intense thrombolytic state. The indications for increasing the infusion rate were either an insufficiently lowered plasminogen concentration or a low value for the isotopic clot dissolution test; a dose increase of 30 to 50 per cent was always sufficient to induce biochemical changes of the desired degree. Though the mean fall of fibrinogen concentration averaged 30 per cent of the initial concentration, sometimes fibrinogen values fell to as low as $100 \mathrm{mg}$. per $100 \mathrm{ml}$. plasma. However, for reasons discussed earlier, in footnote three, it is probable that some of these determinations were misleadingly low and the actual fall in plasma fibrinogen that occurred may be less than stated here. All blood specimens, withdrawn from the patients, clotted in a macroscopically normal manner and the clots were of a sufficiently firm consistency to resist inversion of the specimen tube. Thus, despite the apparent magnitude of the plasma fibrinogen fall in some patients, treatment was never terminated on this account.

The activation of human plasminogen by streptokinase takes place by a two stage reaction (24, 25). First streptokinase reacts with a plasma component (termed proactivator) and the resulting activator reacts with plasminogen enzymati- 


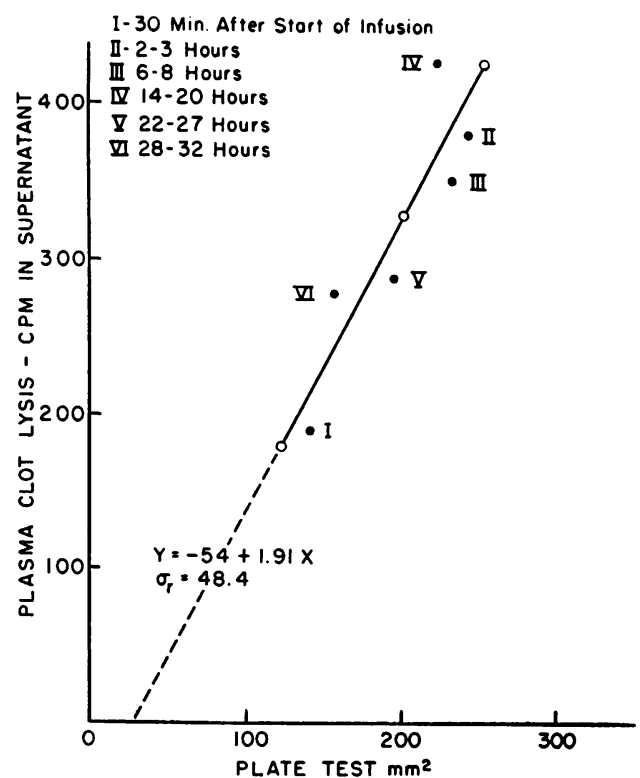

Fig. 2. Plasma Clot Lysis (CPM) Plotted against Fibrin Plate Test at Various Times During StreptoKINASE (SK) INFUSION

A constant ratio between the two tests, the one being sensitive both to the presence of streptokinase-plasma activator and to streptokinase, while the other was sensitive only to the former indicated that activator depletion did not occur $(r=0.88$ and $p=0.02)$.

cally. Proactivator has yet to be isolated or characterized but present evidence suggests that it may be closely associated with or a derivative of plasminogen (26). Since in our patients serum plasminogen concentration has been held at zero or near zero levels for many hours, proactivator concentration could also have fallen sufficiently to impair effective plasma thrombolytic activity. Plasma proactivator concentrations were not assayed directly as the available methods are unsatisfactory but observations on plasma activator concentrations yielded important indirect information. Whereas the isotopic clot dissolution test was susceptible to both the action of streptokinase and to streptokinase induced plasma activator, the fibrin plate test was susceptible only to the latter substance (11). Thus a marked decline in plasma proactivator concentration would have caused an alteration in the ratio of the plasma activities assayed by the two tests. Figure 2 shows (data taken from Table I) that the ratio of plasma activities upon these two tests remained constant regardless of the time after the start of the infusion at which the plasma was drawn. The points lie randomly (with regard to the time after the start of the infusion) along a regression line $(r=$ 0.88 and $p=0.02$ ) and analysis of variance disclosed no evidence of nonlinearity. This observation indicates that the effectiveness of the plasma thrombolytic state was not impaired by lack of proactivator.

\section{Platelet counts}

Serial platelet counts were performed on six patients during the course of therapy. The initial dose of streptokinase varied between 60,000 and 800,000 streptokinase units (100 to $1,300 \mu \mathrm{g}$. protein nitrogen), being assessed individually for each patient on the basis of plasma assay (22) and being injected intravenously over a 15 minute period. The patients selected showed evidence of either a moderate or a high degree of immunization against streptokinase and the 30 hour sustaining infusion was run at a rate of 200 to $400 \mu \mathrm{g}$. streptokinase per hour.

Inspection of the platelet counts failed to show any disturbance in their values as a consequence of the streptokinase administration. The actual counts were: at start $243,000 \pm 59,000 ; 30 \mathrm{~min}$ utes after start $223,000 \pm 78,000$; two to three hours after start $252,000 \pm 73,000$; eight hours after start $309,000 \pm 92,000 ; 12$ hours from start $342,000 \pm 147,000 ; 30$ hours from start at termination of infusion $280,000 \pm 112,000 ; 24$ hours after the termination of the infusion $273,000 \pm$ 98,000 (all values for $\mathrm{p}$ exceed 0.1 ).

\section{Capillary fragility}

Capillary fragility was estimated by the suction cup method (27), at two to six hourly intervals in seven patients receiving 30 hour streptokinase therapy. No change of capillary fragility was found and in no instance were petechial hemorrhages produced at suction pressures of less than $50 \mathrm{~mm}$ mercury.

\section{Serum proteins}

In five patients receiving 30 hour streptokinase therapy one serum sample drawn before the start of therapy, four drawn during its course and one after its termination were examined by paper electrophoresis. Albumin, alpha ${ }_{1}$, alpha $a_{2}$, beta and gamma globulin fractions were estimated by stain- 
TABLE II

Effect of streptokinase therapy upon one stage prothrombin times *

\begin{tabular}{|c|c|c|c|c|c|c|c|c|}
\hline & 0 & $30 \mathrm{~min}$. & $2-3 \mathrm{hr}$. & $6-8 \mathrm{hr}$. & $18 \mathrm{hr}$. & $26 \mathrm{hr}$. & $30 \mathrm{hr}$. & $+6-12 \mathrm{hr}$ \\
\hline $\begin{array}{l}\text { Clotting time in seconds } \\
\pm S \text {. D. }\end{array}$ & $15.9 \pm 1.7$ & $19.8 \pm 4.2$ & $26.5 \pm 11.6$ & $29.9 \pm 11.7$ & $25.4 \pm 3.0$ & $24 \pm 2.5$ & $23.9 \pm 1.9$ & $20.2 \pm 4.3$ \\
\hline Range & $13-19$ & $16-31$ & $21->60$ & $20->60$ & $20-28$ & $22-27$ & $22-27$ & $15-25$ \\
\hline \multicolumn{9}{|c|}{ Steroid treated patients } \\
\hline $\begin{array}{l}\text { Clotting time in seconds } \\
\pm \mathrm{S} . \mathrm{D} \text {. }\end{array}$ & $15.3 \pm 1.2$ & $16.2 \pm 1.2$ & $21.7 \pm 5.1$ & $23.8 \pm 2.2$ & $22.0 \pm 2.7$ & $20.0 \pm 1.7$ & $21.8 \pm 1.0$ & $19.8 \pm 3.4$ \\
\hline Range & $14-17$ & $15-18$ & $17-30$ & $21-26$ & $21-28$ & $18-22$ & $21-23$ & $17-23$ \\
\hline
\end{tabular}

* The effect of supplemental steroid therapy was to diminish the rise in one stage prothrombin time that occurred. Analysis showed that the significance of the difference between the observations recorded over the first eight hour period was $\mathrm{p}=0.02$.

ing the strips and eluting the fractions. No significant alterations of the serum protein fractions were found.

\section{Serum transaminase (SGO-T)}

Serial assays were run in nine patients receiving therapy. No deviations from the base level occurred.

\section{The coagulation defect}

A coagulation defect, demonstrable in every instance by a rise in the one stage prothrombin time, developed in all patients receiving massive streptokinase dosage. Moreover, some of these patients, at or after the time that the one stage prothrombin time was most grossly elevated, experienced clinically evident episodes of untoward bleeding from various anatomic sites. Table II, upper section, shows serial one stage prothrombin times found in treated patients and the hemorrhagic complications are described in the next section on the hemorrhagic diathesis.

One stage prothrombin times commenced to rise immediately following the injection of the priming dose of streptokinase during the initial phase of plasminogen activation. Peak values were usually attained at six to eight hours after which they frequently declined to stabilize at a lower level during the remainder of the infusion period and recovery to normal values for the test took eight to 24 hours after its end. A few patients experienced such a great elevation of their one stage prothrombin times in the first four to eight hour period that treatment had to be terminated. In these patients, following the cessation of the strep- tokinase infusion, a decline toward more normal one stage values was apparent within four hours and virtually normal values were found 16 to 30 hours later.

The pathogenesis of the rapidly developing clotting defect is displayed in Figure 3 . The defect illustrated, the most extreme encountered in our series, developed in a 72 year old male receiving his first streptokinase treatment. Shortly after the start of the infusion the one stage prothrombin time rose rapidly and the patient's plasma developed an intense degree of antithrombin activity,

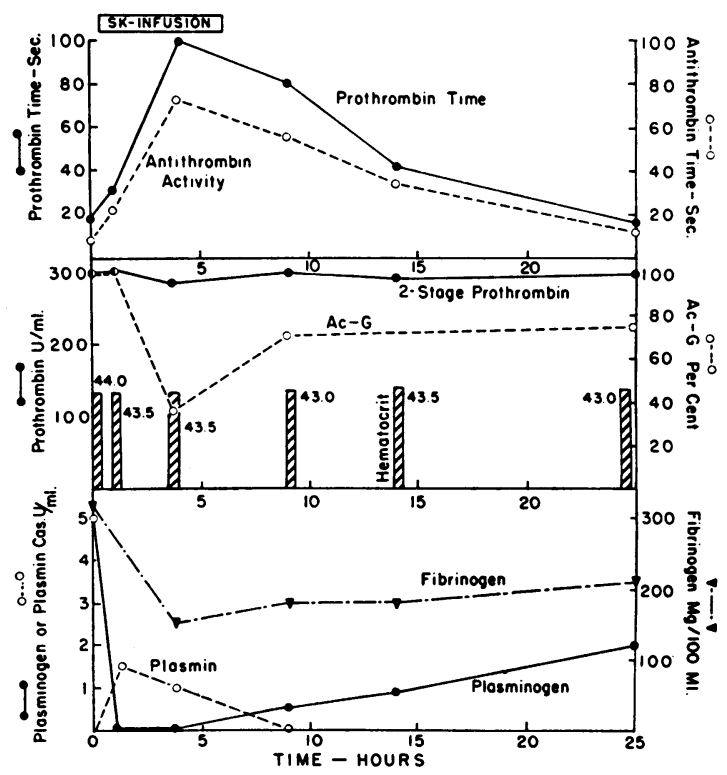

Fig. 3. Extreme Coagulation Defect During STREPTOKINASE THERAPY

Deleterious clinical complications were absent despite the severity of the coagulation defect that necessitated the termination of streptokinase treatment. 


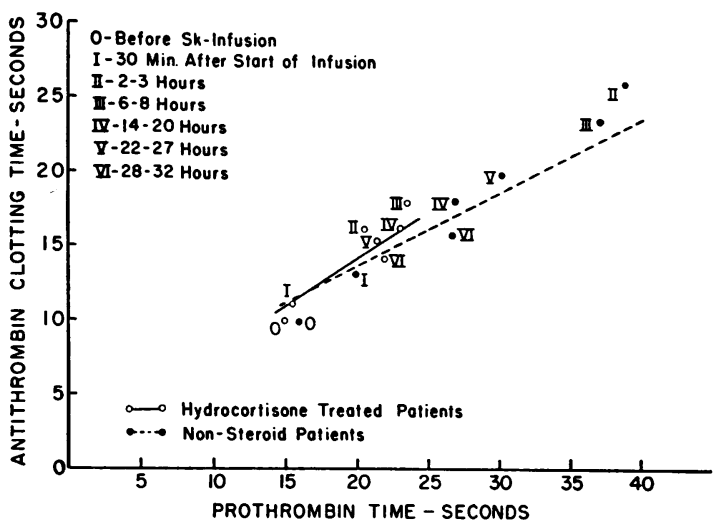

Fig. 4. Relationship Between Prothrombin Time and Antithrombin Clotting Time at Various Times DURING Streptokinase (SK) Infusion

One stage prothrombin times were closely correlated at all stages during the infusion with determinations of plasma antithrombin activity. For nonsteroid treated patients $r=0.93, p<0.001$. Significant differences did not exist $(p>0.1)$ between steroid and nonsteroid treated patients.

which paralleled the prothrombin time rise. Coincidentally a fall of plasma accelerator globulin content was found but quantitatively this was of insufficient degree to have exerted important effects upon the prothrombin time. Whole blood fibrinolysis remained brisk throughout the infusion period and noteworthy was the presence of a high level of circulating plasmin, some fivefold greater than that normally found under these circumstances (11). Despite the development of these gross abnormalities in plasma coagulation moieties, plasma prothrombin concentrations (determined by the two stage test) remained unchanged and whole blood clotting time determinations (made in glass tubes) showed only small and probably insignificant variation. Clinically, the patient showed excessive oozing of blood from venipuncture sites and despite the eventual formation of apparently firm clots, ecchymoses developed in these areas. Serial hematocrit determinations remained unaltered, blood specimens formed normally retracted clots, changes in platelet count did not occur and determinations of capillary vessel fragility remained within normal limits. Repeated examination of stool and urine specimens were negative for blood and other untoward signs or symptoms were absent.

Investigation of other patients has shown iden- tical qualitative changes in the pattern of the coagulation defect, but usually these were of a much lesser degree. Serial assays for accelerator globulin have shown that the mean plasma content (expressed in per cent) was $56 \pm 18$ (range 31 to 100 per cent) at the time of greatest depression, which occurred between two to six hours after the start of the infusion. This fall was normally insufficient to have altered the one stage prothrombin time more than one to two seconds. Certain patients received supplemental hydrocortisone, but analysis revealed no difference $(p>0.1)$ with respect to the degree of change in accelerator globulin depression in the two series. However a very striking correlation was present between the rising one stage prothrombin time and the development of increasing plasma antithrombin activity $(r=0.93 \mathrm{p}<0.001)$; this relationship is illustrated in Figure 4. Such an association offers highly suggestive evidence that the abnormality of the one stage prothrombin time found in our patients resulted from the development of plasma antithrombin activity and further evidence in favor of this contention will be developed.

\section{The effect of hydrocortisone administration on the} induced fibrinolytic state and the clotting defect

During the later stages of the investigation all patients received supplemental intravenous hydrocortisone. Twenty $\mathrm{mg}$. hydrocortisone was given prior to the injection of the first streptokinase dose and steroid administration was continued at the rate of $10 \mathrm{mg}$. per hour for the first eight hours of the infusion and thereafter at the rate of $5 \mathrm{mg}$. per hour until its termination. This schedule was sometimes varied and some patients received only a total of $100 \mathrm{mg}$. hydrocortisone by the intravenous route, maintenance of steroid therapy being accomplished by the use of intramuscular cortisone preparations. Differences were not apparent between the results of the two schedules of steroid administration and the combined patient group is referred to collectively as steroid treated.

Mention has been made earlier that supplemental steroid treatment caused no change in assays for plasminogen concentration, fibrin plate test, or isotopic clot dissolution assays, all of which are shown in Table I. However, despite the fact 
that fibrinogen falls in the two groups (steroid and nonsteroid treated) were similar as were decreases in plasma accelerator globulin $(\mathrm{p}>0.1$ in each instance), striking differences were apparent in the degree of whole blood fibrinolysis recorded. Of 30 blood samples withdrawn from 10 steroid treated patients during the first eight hours of steroid treatment, 20 failed to lyse over a 24 hour observation period; of 48 samples drawn from nonsteroid treated patients during the same period, only six failed to lyse within the same time. Analysis either on the basis of lysis times between the groups or on the basis of lysis or no lysis within the period of observation give $p<0.001$ in each case.

The rise in the one stage prothrombin time following streptokinase treatment was also much reduced by the administration of steroids. The extent of this reduction is given by comparison of the upper and lower sections of Table II : Figure 4 shows a plot of the one stage prothrombin time against the plasma antithrombin activity in the same patients. Analysis of the prothrombin times recorded over the first eight hours of the infusion period between the steroid and the nonsteroid treated groups showed $p$ to be 0.02 . Actually the differences were larger than shown, as on account of the development of excessively elevated one stage times, the streptokinase infusion was sometimes stopped early in the nonsteroid treated group. These changes in laboratory observations were associated with a remarkable reduction in the incidence of toxic effects attributable to the streptokinase treatment. Toxic effects will be referred to in the section on the hemorrhagic diathesis.

Test of the two regression lines shown in Figure 4 indicates that they do not differ significantly $(p>0.1)$, though the fit of the line in the steroid treated patients is noticeably inferior to that found with the nonsteroid treated group. This difference is most easily explained by the differing effect, on a proportional basis, of the substantially equal fall of plasma accelerator globulin that occurred in both groups. Whereas in the steroid treated group the accelerator globulin fall was associated with a relatively minor rise of plasma antithrombin activity, in the other group the rise of antithrombin activity was much greater. This concept is supported, but not proven, by analysis of the proportional defect ratio upon the one stage prothrombin time at various times after the start of the infusion.

In summary, the effect of supplemental steroid treatment was to reduce the rate and degree of whole blood fibrinolysis, to restrain the development of plasma antithrombin activity and thus to reduce the elevation of the one stage prothrombin time that would otherwise have occurred. Changes in other coagulation and fibrinolytic moieties secondary to the use of steroids were not detected.

\section{The hemorrhagic diathesis}

The development of a mild clinical hemorrhagic diathesis was common in those 34 patients treated without supplemental steroid therapy but was seen in only one patient who did receive steroids. Usually the only manifestation of the diathesis was excessive oozing from venipuncture sites and the subsequent appearance of ecchymotic areas related to these sites, though sometimes hematomatas were formed at other injection sites. Occasionally more serious manifestations of a clinical hemorrhagic nature were apparent and these occasions are classified below in connection with certain predisposing factors.

1) Major operative wounds. Since the first stage of wound healing involves the deposition of fibrin, the induction of a thrombolytic state would be expected to cause fibrin lysis and hemorrhage around and into the wound. Nevertheless, provided that hemostatic mechanisms remain unimpaired, the hemorrhage would be expected to be self-limiting, as fibrin laid down during the thrombolytic state would be lacking in plasminogen and thus be insusceptible to autolysis by plasma activator.

Three patients were treated with streptokinase within 12 to 24 hours of major operative intervention. In two patients the femoral, popliteal and posterior tibial arteries had been exposed and in the third the axillary artery. Though in each instance the operation had failed to improve the limb blood supply, the centripetal portion of each deep and extensive wound had a normal blood supply from collaterals and the centrifugal portion a somewhat diminished one. Within six hours of starting streptokinase treatment, the wound margins became grossly ecchymotic, but 
though in each instance they were loosely sutured, only small quantities of blood drained from the wounds, not perceptibly greater in amount than that draining before the start of streptokinase. One patient, just prior to streptokinase therapy, had three large deep wounds inflicted on the arms in an unsuccessful attempt to cannulate a vein. Despite meticulous surgical hemostatic technique, petechial hemorrhages were apparent in the wound margins within four hours of starting streptokinase and large ecchymotic areas were apparent after six hours. However though treatment was given daily for three days and the ecchymotic areas spread to the neck, apparent resolution commenced even while the treatment was being continued.

2) Local disease or trauma. Clinical manifestations of the hemorrhagic diathesis tended to occur, as was not unexepected, at sites of local disease or trauma. A 54 year old male, successfully treated for ileofemoral thrombophlebitis, developed coincidentally with the rapid subsidence of the limb edema a sharp increase in the size of a preexistent knee effusion: A joint tap revealed a bloodstained fluid. This patient also continued to ooze blood from the site of an intramuscular penicillin injection, even after all laboratory evidence of the fibrinolytic state had returned to normal. Three other patients developed large hematomatas at morphia injection sites, an effect probably related to the local pharmacological action of the drug. One patient experienced a small hematemesis following treatment and radiological examination showed a duodenal ulcer. However in view of the time relationship of the treatment and the onset of bleeding, it is possible that the two events were unrelated.

Though the presence of large or relatively large diseased areas appeared to determine the site of bleeding, smaller areas of trauma were without apparent effect. Five patients, prior to and at six hours after the commencement of therapy, were subjected to minor trauma by applying the suction cup of a capillary fragility apparatus at $300 \mathrm{~mm}$. $\mathrm{Hg}$ for five minutes on the forearm. In each instance petechial hemorrhages were produced below the cup. They were observed by low power magnification throughout the infusion course: In no instance did the size or number of the hemorrhages increase.

3) Dicumarot administration. The possible hazard of Dicumarol effect upon the hemorrhagic diathesis was realized at the start of the investigation, but the exigencies of clinical practice required that eight patients who had received one or more doses of Dicumarol ${ }^{\circledR}$ should be treated with streptokinase. Three of these patients, despite the prior administration of $50 \mathrm{mg}$. of vitamin $\mathrm{K}_{1}$ by the intravenous route, developed marked coagulation abnormalities. In the first patient, though excessive oozing accompanied venipuncture, the extent of the coagulation anomaly was only revealed by laboratory study. In the second patient the greatly prolonged one stage prothrombin time (50 seconds at maximum) was associated with minor and transient bleeding from the gums and the demonstration of microscopic hematuria over a two day period. The third patient, a 54 year old male, had been maintained on Dicumarol ${ }^{\circledR}$ for six months, since his first attack of myocardial infarction. At a time when his one stage prothrombin time was 40 seconds, he experienced a further severe attack of myocardial infarction. He was given vitamin $K_{1}$ by the intravenous route but six hours after the start of streptokinase his one stage prothrombin time was 60 seconds. Streptokinase was continued for a further 24 hours by which time his one stage time had declined to 32 seconds. However the area around the infusion needle became grossly ecchymotic, his whole arm became greatly swollen (diameter 7 $\mathrm{cm}$. greater than its fellow) and ecchymotic areas appeared around the axilla. Stools and urine were negative for blood, serum bilirubin remained unaltered and values for platelets, bleeding and clotting times were normal. However over the next 10 days his hematocrit fell 10 points, remained depressed for a week and then commenced to rise. Clinically the patient did well and the arm returned to its normal appearance and function.

4) No apparent predisposing cause. Two other patients have shown falls in hematocrit values of six and eight points, respectively, during treatment, without clinical evidence of bleeding, but in each instance this fall could have been consequent upon the primary disease process.

\section{Autopsy evidence}

Ten patients died either during or after streptokinase treatment. Clinical protocols and a de- 
TABLE III

Predicted dose values and urokinase lysis times of plasma before and after streptokinase (SK) treatment *

\begin{tabular}{|c|c|c|c|}
\hline Time of sampling & Before SK & 1-2 Months after SK & 3-11 Months after SK \\
\hline $\begin{array}{l}\text { Predicted dose test, } S K-U / m l \text {. } \\
\text { Range }\end{array}$ & $\begin{array}{c}28 \pm 15 \\
(5-55)\end{array}$ & $\begin{array}{l}1,760 \pm 1,100 \dagger \\
(900-4,000)\end{array}$ & $\begin{array}{l}70 \pm 21 \\
(20-120)\end{array}$ \\
\hline Urokinase lysis time, min. & $21 \pm 7$ & $18 \pm 9$ & $24 \pm 10$ \\
\hline \multicolumn{4}{|c|}{$\begin{array}{c}\text { Antiplasmin assay of immune and nonimmune plasma expressed as per cent inhibition } \\
\text { of a standard plasmin solution }\end{array}$} \\
\hline Quantity of test plasma & $0.2 \mathrm{ml}$. plasma & $0.1 \mathrm{ml}$. plasma & $.05 \mathrm{ml}$. plasma \\
\hline $\begin{array}{l}\text { Immunized patients } \\
(P . D .1,760 \pm 1,100 S K-U / \mathrm{ml} .) \\
\text { per cent inhibition }\end{array}$ & $70 \pm 8$ & $55 \pm 6$ & $38 \pm 8$ \\
\hline $\begin{array}{l}\text { Nonimmune patients } \\
(P . D .32 \pm 10 S K-U / m l .) \\
\text { per cent inhibition }\end{array}$ & $68 \pm 7$ & $58 \pm 6$ & $39 \pm 6$ \\
\hline
\end{tabular}

* The upper section illustrates the degree of immunization (on the basis of plasma findings) occurring after streptokinase treatment. The lower section confirms the fact that the data shown resulted from the formation of specific antibody.

$\dagger$ This group is the same as the immunized patients in the lower part of this table.

scription of specific pathological findings are published elsewhere (12), but in no instance was it considered on clinical grounds that the treatment contributed to death. Autopsy permission was refused in the case of a 74 year old woman suffering from myocardial infarction and shock who received only three hours' streptokinase treatment. Three patients died during the course of therapy at seven, 12 and 14 hours, respectively, after its start and a further three patients died one, two and three days, respectively, after its completion. Three more patients died in the two to six week period afterwards. The patients' deaths were so spaced that the likelihood of missing an early or late toxic manifestation of the thrombolytic state was slight. A particular search was made for evidence of untoward old or recent hemorrhage and also for myocardial lesions similar to those described as occurring in rabbits after the injection of crude streptokinase preparations (28). In no instance were pathological findings other than those related to the primary disease observed and in all instances an adequate pathological cause, sufficient to cause death and related to the primary disease, was found.

\section{Immunological consequences}

Streptokinase is antigenic to man (10) and the heavy intravenous dosage required to produce an intense and sustained thrombolytic state invariably, or almost invariably, results in rapid immunization of the patient. Immunization may be of such an extreme degree as to prevent, temporarily at least, further induction of thrombolysis by streptokinase should it be required.

However it has been suggested (29) that treatment of the patient with streptokinase activated plasmin may result not only in the stimulation of antibody formation but also cause an early relatively large and important increase in plasma antiplasmin content. This contention, if true, would imply that a state of impaired physiological thrombolytic activity might follow the therapeutic use of sterptokinase or streptokinase activated plasmin.

Table III (upper portion) shows that though plasma obtained from patients one to three months after streptokinase therapy is relatively insusceptible to the action of streptokinase (requiring 40 - to 200-fold the original streptokinase concentration to produce a fibrinolytic end point $(\mathrm{p}<$ $0.001)$, urokinase retains its former efficacy as a plasminogen activator $(p>0.1)$. This observation suggested that the antiplasmin content of immune and nonimmune plasma was identical. Table III (bottom portion) shows antiplasmin assay made on the one to three month highly immune plasma samples (referred to above) and compared with the antiplasmin content of 17 control nonimmune plasma samples. Since anti- 
plasmin combines with plasmin in a nonlinear manner, these assays were conducted using three different concentrations of spontaneously activated plasmin; the differences in antiplasmin values between the two sets of samples were negligible $(\mathrm{p}>0.1)$.

Plasma samples (35 in number) were withdrawn from nine patients at intervals from one day to one month after streptokinase therapy. All patients became immunized in a manner similar to that displayed in Table III, but in no instance during the course of the immunization process was the urokinase lysis time significantly altered. These results indicate that changes in plasma constituents following the streptokinase induced thrombolytic state are confined to alteration of specific antibody concentration.

A point of practical importance concerns the duration of persisting high plasma antibody levels following streptokinase therapy, since these, if sufficient, may be a bar to retreatment of the patient. We have followed 17 patients and find that antibody levels commence to decline from their peak at two to three months and the fall thereafter is somewhat variable. Antibody levels had fallen to a sufficient degree to render retreatment practicable in nine of the 17 patients after three months and in the remaining patients retreatment could have been undertaken after six months.

\section{DISCUSSION}

Intense plasma thrombolytic states were maintained throughout the streptokinase treatment period with thrombolytic activities, calculated from the radiochemical assays, of 100 to $500 \mu \mathrm{g}$. fibrin lysed per ml. plasma per hour. These activities far exceed any assayed in human subjects treated with adrenalin, electroshock, subjected to pyrogen injection or to procedures involving ischemia of an extremity (30) and are much greater than those developing post mortem after sudden death (31). Theoretically the plasma thrombolytic activities attained should be more than sufficient to produce rapid thrombolysis of emboli or thrombi contained within the lumen of vessels even if generous allowance is made for the poor blood flow adjacent to these regions. Clearly a theoretical contention of this nature requires the support of clinical trial and this trial, considered to provide practical demonstration of the contention's validity, is reported elsewhere (12).

Full activation of plasminogen contained in plasma would cause, were it not for the presence of plasma antiplasmin activity, rapid and extreme reduction of plasma components susceptible to its action and in fact it has been calculated that it would cause total destruction of fibrinogen contained in the body in 15 minutes (32). However, in practice, full activation of plasminogen causes relatively minor changes in plasma constituents susceptible to its action because of the high antiplasmin activity of plasma invariably found. The average normal plasminogen content of plasma is 3.5 casein units per ml. (calculated from Table I), but the average antiplasmin activity (calculated from the data of Table III) is 5.1 casein units per $\mathrm{ml}$. As has been mentioned earlier, the calculation of antiplasmin values is to a degree arbitrary as it is influenced by the time allowed for plasmin antiplasmin interaction prior to completion of the assay, but our present data indicate that, at least in healthy persons, the antiplasmin content of plasma normally exceeds its potential plasmin activity.

The evidence advanced in this and preceding communications $(30,11)$ suggests certain new concepts concerning the nature of physiological and pathological fibrinolytic phenomena. The presence of plasminogen in plasma and the obvious manifestations of fibrinolytic phenomena in this fluid have focused attention on what are apparently associated consequences of the thrombolytic state rather than on the primary mechanism of thrombolysis. The hypothesis that best explains the present data would imply that plasma fibrinolytic phenomena (hereafter referred to as "fibrinolytic" phenomena) occur as an incidental consequence of the transport by plasma of plasminogen system components. Plasminogen is present almost exclusively as a plasma component, but physiologically (as concerns its function in thrombolysis) may be regarded as inactive in this milieu and its function appears to be to endow newly formed thrombi or other fibrinous deposit with a proenzyme, which on activation is capable of effecting its lysis. In the presence of plasminogen activators, by which thrombolysis may be mediated, the inhibitory action of plasma serves as a safeguard to prevent uncontrolled enzymatic 
change in the plasma, but on occasion this safeguard proves insufficient and manifestations of "fibrinolysis" as a disease state become apparent.

Hemorrhagic phenomena are frequently observed in patients, who spontaneously develop "fibrinolysis" usually following obstetric complications or after surgery. However, owing to the relatively transient nature of the complication and the frequently critical condition of the patient, the opportunities for study of this state have been limited. The present investigation has provided a unique opportunity for such study as the 50 patients in our series experienced the biochemical changes incident to an intense thrombolytic ("fibrinolytic") state for continuous periods from five to 42 hours; in 34 of them the duration was 30 hours.

Experience shows that the hemorrhagic diathesis was not an invariable accompaniment of the thrombolytic state. Falls of plasma AcG occurred equally in those patients who did or did not exhibit the diathesis and appeared to exert an insignificant effect upon its pathogenesis. It is of incidental interest that the recently described compound, vitamin KS II (33), was shown in two patients to be ineffective in the prevention of the defect. A substantial rise of plasma antithrombin activity was invariably demonstrable preceding and during the course of the diathesis or its complications and its prevention by steroids markedly reduced the incidence of this diathesis. The one stage prothrombin time was closely correlated with the degree of plasma antithrombin activity (Figure 4) and unless the prothrombin time exceeded 30 seconds, gross evidence of the diathesis was lacking. However, bleeding occurred infrequently even in the presence of intense thrombolytic states and a severe coagulation defect. Several of our patients experienced both conditions for periods of many hours, the only clinical manifestations of the diathesis being related to bleeding from venipuncture sites with the subsequent formation of ecchymoses in these areas. These observations would seem to follow as a corollary to our findings that capillary fragility remained normal and that fibrin laid down in a plasminogenpoor or plasminogen-free milieu was virtually insusceptible to thrombolysis (11) because of lack of plasminogen within its substance. However the presence of a coagulation defect of sufficient degree could, but need not necessarily, impede hemostasis to such a degree that small hemorrhages secondary to the thrombolytic state might continue unchecked. von Kaulla and Swan (34) who investigated "fibrinolysis" secondary to the use of the heart-lung machine in open cardiac operations have noted similar findings and have come to the same conclusion.

Confirmatory to these general views is the evidence that Dicumarol ${ }^{\circledR}$, which increased the magnitude of the coagulation defect, and local disease or trauma, which provided a focus for hemorrhage to occur, both acted as predisposing causes to the development of clinical hemorrhagic manifestations. Bleeding into the margins of wounds is a special case and occurs independent of the hemorrhagic diathesis, being a predictable result of the induced thrombolytic state and a manifestation of its activity. Nevertheless, if the wounds were in deep and inaccessible sites, we have regarded this feature as a total contraindication to the induction of the thrombolytic state. If anything less than the most meticulous hemostatic technique were employed at the original operation, the dangers of bleeding from a thrombosed, but unsutured vessel, must be considerable.

Plasma antithrombin activity developing during the thrombolytic state has properties different from the conventionally described entities antithrombins I-IV (35). There is, however, a close resemblance between the antithrombin activity found in our patients and that described recently by Loeliger and Hers (36) as "antithrombin V," which term they applied to the antithrombin activity apparent in the plasma of a patient suffering from rheumatoid arthritis. We have evidence to suggest that the antithrombin activity present in our patients was at least partly due to the presence of fibrinogen breakdown products but characterization is as yet insufficiently advanced to be certain that this factor represents the total antithrombin effect. However this finding might account, at least partly, for the dramatic effect of steroid administration in the prevention of the hemorrhagic diathesis. Following steroid administration, patients showed a greatly reduced degree of whole blood fibrinolysis over the control series $(p<0.001)$ and this change may have caused a diminished production of fibrinogen 
breakdown products. $^{10}$ Also we have noted, though as yet this cannot be proven on a statistical basis, that severe manifestations of the hemorrhagic diathesis occurred only in those patients in whom relatively high free plasmin concentrations were demonstrable, a finding in accord with the suggestion that plasma antithrombin activity may be related to the presence of fibrinogen breakdown products.

Hitherto the term "fibrinolysis" or the "fibrinolytic state" has been used to embrace both thrombolytic and plasma proteolytic manifestations. The separation of this complex phenomenon into two distinct entities has important clinical and therapeutic implications. First, it is clear that thrombolysis may occur independently of plasma proteolysis and the independence of these two reactions was demonstrated in our patients. Secondly, hydrocortisone administration greatly reduced the incidence of undesirable proteolytic phenomena without impairment to the thrombolytic state; refinement of this and other precautions should permit the development of simple therapeutic regimes. Lastly, clarification of the mechanism and associated features of the enhanced proteolytic state has allowed of its recognition in a number of disease conditions (37) where its presence has not hitherto been described.

\section{SUMMARY}

1. Thrombolytic states of long duration ( 30 hours) and of great intensity (plasma activities of 100 to $500 \mu \mathrm{g}$. fibrin lysed per hour per $\mathrm{ml}$. plasma) have been produced in man by the intravenous infusion of streptokinase.

2. Normally the thrombolytic state was well tolerated, but some patients developed a hemorrhagic diathesis of mild to moderate severity. The aberrations contributing to the development of this diathesis have been partially elucidated and the concurrent use of intravenous hydrocortisone has been shown to prevent or at least greatly reduce the severity of the hemorrhagic diathesis.

3. It was concluded that the induced thrombolytic state was well tolerated by man and that its

\footnotetext{
10 The observation that fibrinogen levels in steroid treated patients did not differ significantly from those in the nonsteroid treated group does not exclude this hypothesis since fibrinogen breakdown products may influence the fibrinogen assay.
}

use as a therapeutic tool in the treatment of thromboembolic disease was worthy of further investigation.

\section{ACKNOWLEDGMENTS}

It is a pleasure to record our indebtedness to Miss Geraldine Nelson and Mr. Charles Chisenhall for technical assistance; to Dr. William Harrington whose laboratory made all the platelet counts; to Dr. Jack Hasson who performed the majority of the autopsy examinations and to the many physicians on the staffs of the Barnes and Jewish Hospitals who referred patients for streptokinase treatment.

\section{REFERENCES}

1. Sherry, S., Titchener, A., Gottesman, L., Wasserman, P., and Troll, W. The enzymatic dissolution of experimental arterial thrombi in the dog by trypsin, chymotrypsin and plasminogen activators. J. clin. Invest. 1954, 33, 1303.

2. Johnson, A. J., and Tillett, W. S. The lysis in rabbits of intravascular blood clots by the streptococcal fibrinolytic system (streptokinase). J. exp. Med. 1952, 95, 449.

3. Sherry, S., Callaway, D., and Freiberg, R. Prevention of postoperative adhesions in the dog by intravenous injections of plasminogen activators. Proc. Soc. exp. Biol. (N. Y.) 1955, 90, 1.

4. Condie, R. M., Hong, C. Y., and Good, R. A. Reversal of the lesions of the generalized Shwartzman phenomenon by treatment of rabbits with streptokinase (abstract). J. Lab. clin. Med. 1957, 50, 803.

5. Tillett, W. S., Johnson, A. J., and McCarty, W. R. The intravenous infusion of the streptococcal fibrinolytic principle (streptokinase) into patients. J. clin. Invest. 1955, 34, 169.

6. Cliffton, E. E. The use of plasmin in humans. Ann. N. Y. Acad. Sci. 1957, 68, 209.

7. Ambrus, J. L., Ambrus, C. M., Back, N., Sokal, J. E., and Collins, G. L. Clinical and experimental studies on fibrinolytic enzymes. Ann. N. Y. Acad. Sci. 1957, 68, 97.

8. Fletcher, A. P., and Johnson, A. J. Methods employed for purification of streptokinase. Proc. Soc. exp. Biol. (N. Y.) 1957, 94, 233.

9. Johnson, A. J., Fletcher, A. P., McCarty, W. R., and Tillett, W. S. The effects in patients of intravenous infusions of purified streptokinase preparations. Proc. Soc. exp. Biol. (N. Y.) 1957, 94, 254.

10. Fletcher, A. P., Alkjaersig, N., and Sherry, S. The clearance of heterologous protein from the circulation of normal and immunized man. J. clin. Invest. 1958, 37, 1306.

11. Alkjaersig, N., Fletcher, A. P., and Sherry, S. The mechanism of clot dissolution by plasmin. J. clin. Invest. 1959, 38, 1086. 
12. Fletcher, A. P., Sherry, S., Alkjaersig, N., Smyrniotis, F. E., and Jick, S. The maintenance of a sustained thrombolytic state in man. II. Clinical observations on patients with myocardial infarction and other thromboembolic disorders. J. clin. Invest. 1959, 38, 1111.

13. Block, R. J., Durrum, E. L., and Zweig, G. A Manual of Paper Chromatography and Paper Electrophoresis. New York, Academic Press Inc., 1958.

14. Alkjaersig, N., Fletcher, A. P., and Sherry, S. The activation of human plasminogen. I. Spontaneous activation in glycerol. J. biol. Chem. 1958, 233, 81.

15. Sherry, S., and Alkjaersig, N. Biochemical, experimental, and clinical studies of proteolytic enzymes: With particular reference to the fibrinolytic enzyme of human plasma. Ann. N. Y. Acad. Sci. 1957, 68, 52.

16. Quick, A. J. On quantitative estimation of prothrombin. Amer. J. clin. Path. 1945, 15, 560.

17. Ware, A. G., and Seegers, W. H. Two-stage procedure for the quantitative determination of prothrombin concentration. Amer. J. clin. Path. 1949, 19, 471.

18. Deutsch, E., and Schaden, W. Zur Reinigung und Charakterisierung des VII. Blutgerinnungsfaktors. Biochem. Z. 1953, 324, 266.

19. Ware, A. G., and Seegers, W. H. Plasma accelerator globulin: Partial purification, quantitative determination, and properties. J. biol. Chem. 1948, 172, 699.

20. Seegers, W. H., and Smith, H. P. Factors which influence the activity of purified thrombin. Amer. J. Physiol. 1942, 137, 348.

21. Karmen, A., Wróblewski, F., and LaDue, J. S. Transaminase activity in human blood. J. clin. Invest. 1955, 34, 126.

22. Johnson, A. J., Fletcher, A. P., McCarty, W. R., and Tillett, W. S. The intravascular use of streptokinase. Ann. N. Y. Acad. Sci. 1957, 68, 201.

23. Sherry, S., Fletcher, A. P., and Alkjaersig, N. The fibrinolysin system: Some physiological considerations in Symposium on Connective Tissue, Thrombosis, and Atherosclerosis. New York, Academic Press Inc. In press.
24. Müllertz, S. Formation and properties of the activator of plasminogen and of human and bovine plasmin. Biochem. J. 1955, 61, 424.

25. Troll, W., and Sherry, S. The activation of human plasminogen by streptokinase. J. biol. Chem. 1955, 213, 881.

26. Sherry, S., and Alkjaersig, N. Studies on the fibrinolytic enzyme of human plasma. Thromb. Diath. haem. 1957, 1, 264.

27. Lindquist, N. Studien über die cutane Capillarresistenz im Kindesalter. Acta paediat. (Uppsala). 1937, 20, Suppl. 2, 1.

28. Kellner, A., and Robertson, T. Selective necrosis of cardiac and skeletal muscle induced experimentally by means of proteolytic enzyme solutions given intravenously. J. exp. Med. 1954, 99, 387.

29. Back, N., Ambrus, J. L., Simpson, C. L., and Shulman, S. Study on the effect of streptokinase-activated plasmin (fibrinolysin) on clots in various stages of organization. J. clin. Invest. 1958, 37, 864.

30. Sherry, S., Lindemeyer, R. I., Fletcher, A. P., and Alkjaersig, N. Studies on enhanced fibrinolytic activity in man. J. clin. Invest. 1959, 38, 810.

31. Müllertz, S. Fibrinolytic activity of human blood after death. Acta physiol. scand. 1952, 27, 265.

32. Macfarlane, R. G., and Biggs, R. Fibrinolysis. Its mechanism and significance. Blood 1948, 3, 1167.

33. Carter, J. R., and Warner, E. D. Correction of defects in clotting accelerator activity by administration of methionine and vitamin $\mathrm{K}$ and of a new sulfhydryl-substituted methylnaphthoquinone, vitamin K-S (II). J. clin. Invest. 1958, 37, 70.

34. von Kaulla, K. N., and Swan, H. Clotting deviations in man during cardiac bypass: Fibrinolysis and circulating anticoagulant. J. thorac. Surg. 1958, 36, 519.

35. Seegers, W. H., Johnson, J. F., and Fell, C. An antithrombin reaction related to prothrombin activation. Amer. J. Physiol. 1954, 176, 97.

36. Loeliger, A., and Hers, J. F. P. Chronic antithrombinaemia (antithrombin 5 with haemorrhagic diathesis in a case of rheumatoid arthritis with hypergammaglobulinaemia. Thromb. Diath. haem. 1957, 1, 499.

37. Alkjaersig, N., Fletcher, A. P., and Sherry, S. Unpublished observations. 